\title{
In Silico Screening of Traditional Herbal Medicine Derived Chemical Constituents for Possible Potential Inhibition against SARS-CoV-2
}

\author{
R. Srimathi ${ }^{1}$, Muthu K. Mohan Maruga Raja ${ }^{2}$ and Muthu K. Kathiravan ${ }^{3 *}$ \\ 'Department of Pharmaceutical Chemistry, SRM College of Pharmacy, SRMIST, Kattankulathur, \\ Kancheepuram - 603203, Tamil Nadu, India \\ 2Department of Pharmacognosy and Phytochemistry, Parul Institute of Pharmacy \& Research, \\ Parul University, Waghodia - 391760, Gujarat, India \\ ${ }^{3}$ Dr APJ Abdul Kalam Research Lab, SRM College of Pharmacy, SRMIST, Kattankulathur, \\ Kancheepuram - 603203, Tamil Nadu, India; drmkkathir@gmail.com
}

\begin{abstract}
The outbreak of SARS-CoV-2 has initiated an exploration to find an efficient anti-viral agent. From the previous scientific studies of traditional herbal medicines like garlic, ginger, onion, turmeric, chilli, cinchona and pepper, 131 chemical constituents were identified. The filtered search of drug-like-molecules searched using Datawarrior resulted in 13 active constituents (apoquinine, catechin, cinchonidine, cinchonine, cuprediene, epicatechin, epiprocurcumenol, epiquinine, procurcumenol, quinidine, quinine, zedoaronediol, procurcumadiol) showed no mutagenic, carcinogenic or toxic properties. In silico study of these 13 compounds with the best binding affinity towards SARS-CoV-2 protease was carried out. The ligands were subjected to molecular docking using Autodock Vina. Epicatechin and apoquine showed highest binding affinity of -7 and $-7.5 \mathrm{kcal} / \mathrm{mol}$ while catechin and epicatechin showed four hydrogen bond interactions. It is interesting and worth noticing the interaction of GLU166 residue with the ligand in most of the constituents. The effectiveness of catechin and epicatechin as an antiviral agent could be tested against COVID-19.
\end{abstract}

Keywords: COVID-19, Catechin, Epicatechin, Data Warrior, Molecular Docking, Plant Products

\section{Introduction}

On December 30, 2019, the epicenter of the novel coronavirus was first reported in the provinces of Hubei P. R. China. The contagious disease has seen its massive expansion in a short span of about three months by spreading to more than 190 countries and infecting 31 lakhs, causing over 2 lakh casualties worldwide as of April 28, 2020 ${ }^{1}$. In spite of the available protease inhibitors in the treatment of viral infections, WHO said there is no medicine to prevent or cure SARS-CoV-2. Analyzing the treatment strategies for the epidemic that occurred in 2002, SARS coronavirus (SARS-CoV), it is observed that Traditional Chinese Medicine (TCM) has found to modulate $\mathrm{T}$ cells enhancing the host defensive mechanism ${ }^{2}$. A research paper in Lancet indicates glycyrrhizin from liquorice root inhibited viral replication in $\mathrm{SARS}^{3}$.

Among the four classes of coronaviruses, severe acute respiratory syndrome virus (SARS- CoV2) belongs to beta type ${ }^{4}$. The beta-coronavirus has glycosylated spike (S) protein invading host cells. This $S$ protein binds to angiotensin-converting enzyme 2 $(\mathrm{ACE} 2)^{5-7}$. This binding affinity is higher than that of

\section{${ }^{*}$ Author for correspondence}


SARS-CoV ${ }^{8-11}$. The COVID-19 is a non-segmented enveloped positive sense RNA virus, $\beta$ coronavirus. The genome consists of $\sim 30,000$ nucleotides. It is replicated by a replicase gene that codes for two proteins, ppla and pplab, required for viral transcription and replication. The viral main protease $\left(\mathrm{M}^{\mathrm{pro}}\right)$ digests the polyprotein thereby causing auto-cleavage of the enzyme itself from ppla and pp1b. Targeting $\mathrm{M}^{\text {pro }}$ in the viral life cycle would prove an attractive target for the deadly virus ${ }^{12}$.

Nature provides diversified simplest to complex structures. They have evolved over a long period of time for better interactions with biomolecules. The existing antiviral drugs from natural products are zanamivir, peramivir and lanamivir octanoate ${ }^{13}$. Virtual screening is one of the most powerful tool in drug discovery. The development of a novel candidate for SARS-CoV-2 by a medicinal chemist would take several months or even years till it is marketed. However, to combat the disease at the earliest, an immediate treatment is the vital requirement of the hour.

In an attempt to find the use of traditional herbs, an in-silico based screening ${ }^{14}$ was carried out by using computational methods to scientifically prove the efficacy of these herbs against SARS-CoV-2. Chemical constituents of herbs having a long history of traditional use against infectious disease were selected for the study ${ }^{15}$. We herein report the identification of natural compounds in comparison with N3 inhibitor (N-[(5-methylisoxazol-3-yl) carbonyl] alanyl-1-valyl-n 1 - ((1r,2z)-4-(benzyloxy)-4-oxo1-\{[(3r)-2-oxopyrrolidin-3-yl] methyl $\}$ but-2-enyl)-1leucinamide $)^{16}$. The study will be further extended to see its effect on ACE 2 and inflammation mediators. In addition, ADMET, toxicity, drug likeliness was predicted along with molecular dynamics simulations ${ }^{17}$.

\section{Material and Methods}

The validated computational approach was developed by collecting the $3 \mathrm{D}$ structures of chemical constituents of traditionally used plant products. The downloaded database was further subjected to toxicity screening using Datawarrior v.4.5.1 software ${ }^{18}$. The filtered constituents were identified for their binding affinity towards the target using Autodock Vina ${ }^{19}$. The constituents with greater binding affinity were then docked using Autodock ${ }^{20}$. Figure 1 depicts the protocol of this study.

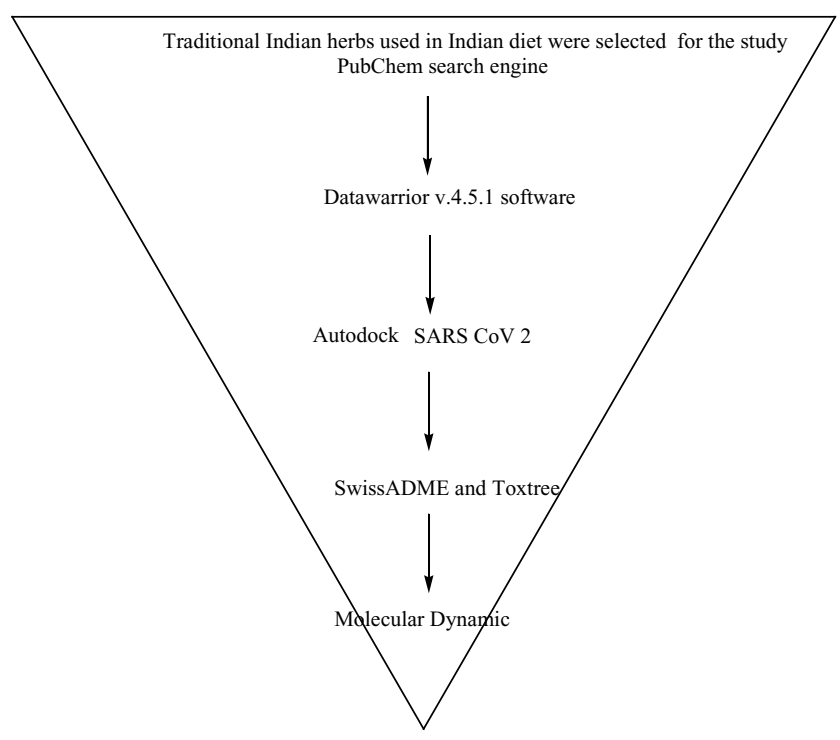

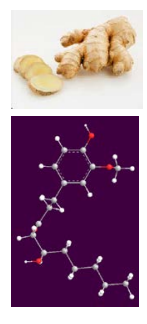

6-Gingerol

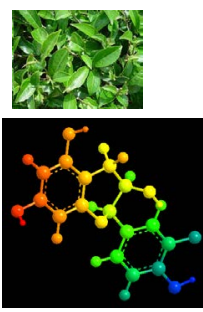

Epicatechin

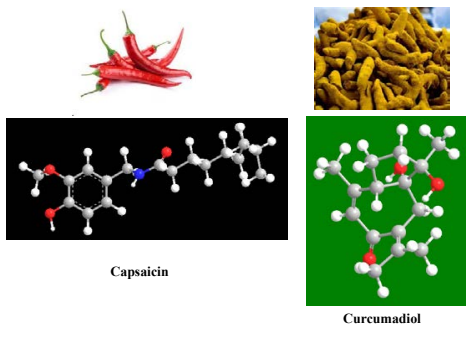

Curcumadiol
Figure 1. The screening strategy and key chemical constituents from Indian plants.

\subsection{Generation of Plant Product Database}

The 131 chemical constituents were identified from traditionally used plant materials ${ }^{21}$ such as garlic, ginger, onion, turmeric, chilli, cinchona and pepper. Their chemical structures were collected from PubChem search engine. The dataset collected consisted of major and minor active constituents, which were then screened for toxicity properties, mutagenic, carcinogenic and druglikeness score. Datawarrior v.4.5.1 software was used. Lipinski's rule of five (RO5) and Vebber's rule was applied. The filtered ligands were selected for further processing.

\subsection{Preparation of 6LU7 Structure}

The three-dimensional structure of SARS-CoV-2 main protease in complex, with an inhibitor N3 was obtained 
from the Protein Data Bank [PDB: 6LU7] ${ }^{22}$. Further, water molecules and inhibitors N3 (Michael acceptor inhibitor) complexed with the protein were removed using Swiss PDB viewer and saved as $p d b$ file for further virtual screening and docking.

\subsection{Virtual Screening using Autodock Vina}

Virtual screening of the ligands was carried out using Autodock Vina. Vina is more efficient in calculating the binding affinity $(\mathrm{kcal} / \mathrm{mol})$, and low energy binding affinity indicates stronger binding of the ligand with the receptor. Vina was selected over AutoDock 4 for its accuracy and speed in selecting the compounds which showed better binding affinity towards the target. The ligand files were prepared as .pdbqt and the macromolecule was added in the receptor. The grid box was centered on the active site at $-11.062 \star 5.943 \star 70.793$ in the dimensions of $\mathrm{x}, \mathrm{y}$ and $\mathrm{z}$ using $1.000 \AA$ spacing.

\subsection{Molecular Docking}

The screened ligands using AutoDock Vina were further subjected to docking simulation using AutoDock 4.0 suite as molecular-docking tool. The protein was downloaded from the protein data bank and prepared using the protein preparation wizard of the Graphical User Interface program "AutoDock Tools" by removing the polar hydrogens, by addition of Kollman charges and was saved in .pdbqt format. The ligands were defined with their torsional roots and were allowed to rotate freely. The grid was centered in the active site region and the grid box size was set at 60,60 and $60 \AA$ and the $\mathrm{x}, \mathrm{y}$ and $\mathrm{z}$ dimensions were $-11.062 \star 5.943 * 70.793$ respectively. AutoDock 4.0 program using the Lamarckian Genetic Algorithm (LGA) was chosen to identify the best conformers and the top 10 conformers were generated for each compound and studied.

\subsection{Bioavailability and Pharmacokinetic Prediction}

The physicochemical properties of the top ligand were subjected to SwissADME ${ }^{23}$ and Toxtree v2.6.13 software ${ }^{24}$.

\section{Results and Discussion}

\subsection{Initial Screening of Active Chemical Constituents from Plant Products}

The natural plant products with antiviral activity was identified by their major and minor active chemical constituents. About 131 structures from plants such as ginger, garlic, onion, turmeric, cinchona, neem, chilli and pepper were downloaded from PubChem database in .sdf format file. From ancient times, it is believed that natural plant products used as traditional foods have a great healing power against microbes. Initial screening of the constituents was performed using Datawarrior v.4.5.1. Software to eliminate the undesirable compounds by following Lipinski's RO5, which states that molecular weight $<500$ Daltons, $\log \mathrm{P}$ should be lower than -1.5 and higher than 6.5, hydrogen bond acceptor $<10$ and hydrogen bond donor $<5$. The chemical constituents that defy this criterion were eliminated. The Total Polar Surface Area (TPSA) greater than $180 \AA^{2}$ and having rotatable bonds higher than 14 were also removed.

About 30 compounds did not satisfy Lipinski's RO5, 24 were found to have toxicity properties and 64 compounds were eliminated as they failed to have a druglikeness score of 0 . It was identified that only 13 chemical constituents passed all the parameters and were used in the study. They are apoquinine, cinchonidine, cinchonine, cupreidine, epi-quinine, quinine, guanidine, epiprocurcumenol, procurcumadiol, procurcumenol, zedoronediol, catechin and epicatechin. These compounds were preprocessed and used in docking simulations. Further, the drug likeness of the compounds was considered using the drug likeness score and the compounds were selected that had a score of above 0 (Tables 1,2 ).

\subsection{Binding Affinity of the Screened Chemical Constituents}

With the identification of 13 chemical constituents that showed drug-like-properties, the calculation for the compound with the best binding affinity towards 
Table 1. The Pharmacokinetic properties, oral bioavailability and toxicity prediction

\begin{tabular}{|c|c|c|c|c|c|c|c|c|c|}
\hline \multirow[b]{2}{*}{ S.No } & \multirow{2}{*}{$\begin{array}{l}\text { PUBCHEM } \\
\text { ID }\end{array}$} & \multicolumn{4}{|c|}{ Pharmacokinetics } & \multirow{2}{*}{$\begin{array}{c}\text { Med } \\
\text { Chem } \\
\text { PAINS }\end{array}$} & \multirow{2}{*}{$\begin{array}{c}\text { Med } \\
\text { Chem } \\
\text { PAINS }\end{array}$} & \multicolumn{2}{|c|}{$\begin{array}{c}\text { Oral } \\
\text { Bioavailability }\end{array}$} \\
\hline & & $\begin{array}{c}\text { GI } \\
\text { Absorption }\end{array}$ & $\begin{array}{l}\text { Bioavailability } \\
\text { Score }\end{array}$ & $\begin{array}{c}\text { CYP } \\
\text { inhibitor }\end{array}$ & $\begin{array}{l}\text { Solubility } \\
\text { Index }\end{array}$ & & & Veber & Egan \\
\hline 1. & 101600159 & High & 0.55 & CYP2D6 & Good & 0 & 0 & Good & Good \\
\hline 2. & 9064 & High & 0.55 & None & Good & 0 & 0 & Good & Good \\
\hline 3. & 101744 & High & 0.55 & CYP2D6 & $\begin{array}{l}\text { Moderately } \\
\text { soluble }\end{array}$ & 0 & 0 & Good & Good \\
\hline 4. & 90454 & High & 0.55 & CYP2D6 & $\begin{array}{l}\text { Moderately } \\
\text { soluble }\end{array}$ & 0 & 0 & Good & Good \\
\hline 5. & 54991 & High & 0.55 & $\begin{array}{l}\text { CYP2D6 \& } \\
\text { CYP3A4 }\end{array}$ & Good & 0 & 0 & Good & Good \\
\hline 6. & 72276 & High & 0.55 & None & Good & 1 & 1 & Good & Good \\
\hline 7. & 10263440 & High & 0.55 & None & Good & 0 & 0 & Good & Good \\
\hline 8. & 10448938 & High & 0.55 & CYP2D6 & $\begin{array}{l}\text { Moderately } \\
\text { soluble }\end{array}$ & 0 & 0 & Good & Good \\
\hline 9. & 189061 & High & 0.55 & None & Good & 0 & 0 & Good & Good \\
\hline 10. & 441074 & High & 0.55 & CYP2D6 & $\begin{array}{l}\text { Moderately } \\
\text { soluble }\end{array}$ & 0 & 0 & Good & Good \\
\hline 11. & 3034034 & High & 0.55 & CYP2D6 & $\begin{array}{l}\text { Moderately } \\
\text { soluble }\end{array}$ & 0 & 0 & Good & Good \\
\hline 12. & 101792719 & High & 0.55 & None & Good & 0 & 0 & Good & Good \\
\hline 13. & 14633011 & High & 0.55 & None & Good & 0 & 0 & Good & Good \\
\hline
\end{tabular}

Table 2. The key features of active constituents

\begin{tabular}{ccccc} 
S. No & Compound & Michael acceptor & Leadlikeness & Synthetic Accessibility \\
\hline 1. & Apoquinine & No & Yes & 4.25 \\
2. & Catechin & No & Yes & 3.50 \\
3. & Cinchonidine & No & Yes & 4.18 \\
4. & Cinchonine & No & Yes & 4.18 \\
5. & Cuprediene & No & No (1 violation) MW >350 & 4.47 \\
6. & Epicatechin & No & Yes & 3.50 \\
7. & Epiprocurcumenol & Yes & No (1 violation) $\mathbf{M W}<\mathbf{2 5 0}$ & $\mathbf{4 . 0 4}$ \\
8. & Epiquinine & No & Yes & 4.34 \\
9. & Procurcumenol & Yes & No (1 violation) $\mathbf{M W}<\mathbf{2 5 0}$ & $\mathbf{4 . 0 4}$ \\
10. & Quinidine & No & Yes & 4.34 \\
11. & Quinine & No & Yes & 4.34 \\
12. & Zedoaronediol & Yes & Yes & $\mathbf{4 . 1 3}$ \\
13. & Procurcumadiol & Yes & Yes & $\mathbf{4 . 3 0}$ \\
\hline
\end{tabular}


SARS-CoV-2 protease was carried out. In comparison to $\mathrm{N} 3$, the five best scoring chemical constituents were apoquinine from cinchona with highest binding affinity of $-7.5 \mathrm{kcal} / \mathrm{mol}$, epicatechin from neem with $-7.0 \mathrm{kcal} / \mathrm{mol}$, catechin from neem with $-6.8 \mathrm{kcal} / \mathrm{mol}$, procurcumenol from turmeric and quinidine from cinchona both having similar score of $-6.6 \mathrm{kal} / \mathrm{mol}$ (Table 3).

\subsection{Molecular Docking}

The constituents that showed higher binding affinity towards the protein were docked with SARS-CoV-2 main protease to estimate the binding energies. Molecular docking is a tool that predicts the conformation of a ligand in the active site of the receptor. SARS$\mathrm{CoV}-2 \mathrm{M}^{\text {pro }}$ is a dimer which consists of protomer A and protomer B. Each protomer is made up of three domains, Domain I (8-102), Domain II (102-184) which are antiparallel $\beta$-barrel structures and Domain III (201-303) which is a five $\alpha$ helix structure arranged in antiparallel structure. The substrate binding site of COVID-19 virus $\mathrm{M}^{\text {pro }}$ is located in a cleft between Domain I (residues 8-101) and II (residues 102-184) and it has a Cys-His catalytic dyad. The binding pocket identified within the residues 189-191 of the long strand and was selected as the active site of the protein.

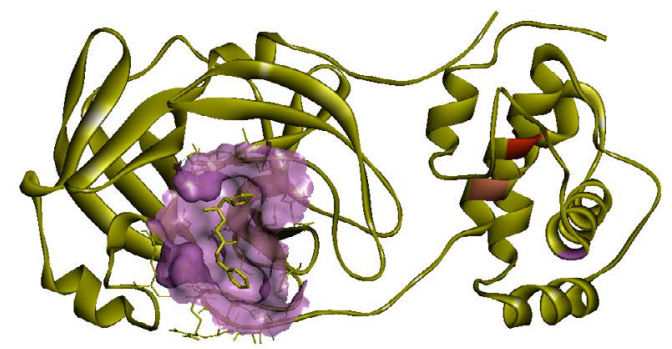

(a)

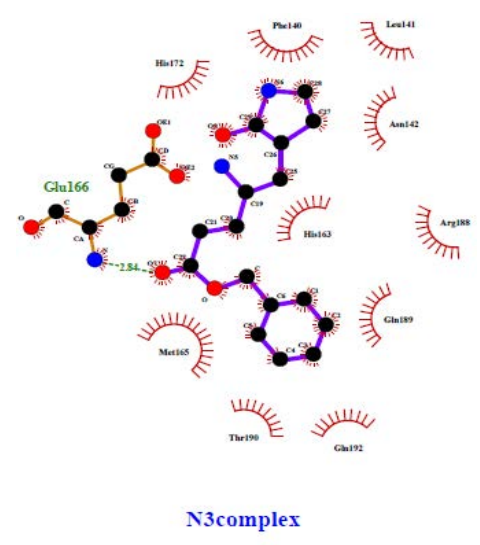

(b)

Figure 2. (a)SARS-CoV-2 main protease is represented in yellow. The N3 ligand docked in $6 \mathrm{LU} 7$ is shown in the hydrophobic pocket (b) 2D interaction maps of N3 inhibitor complex with pocket aminoacids.

Table 3. Binding energy, affinity and key amino acid interactions calculations using AutoDock Vina

\begin{tabular}{|c|c|c|c|c|}
\hline S.No & Compound & $\begin{array}{l}\text { Binding Affinity } \\
\text { (kcal/mol) }\end{array}$ & $\begin{array}{l}\text { Binding Energy } \\
\text { (kcal/mol) }\end{array}$ & Hydrogen Bonds Formed \\
\hline 1. & Apoquinine & -7.5 & -7.7 & GLU166 \\
\hline 2. & Catechin & -6.8 & -8.38 & GLU166,THR190,GLN192,ASP187 \\
\hline 3. & Cinchonidine & -6.5 & -7.59 & GLN189 \\
\hline 4. & Cinchonine & -6.6 & -7.49 & GLU166 \\
\hline 5. & Cuprediene & -6.5 & -7.31 & No Hydrogen Bonds are formed \\
\hline 6. & Epicatechin & -7 & -7.29 & ASP187,GLN189,GLN192 \\
\hline 7. & Epiprocurcumenol & -6.2 & -6.83 & GLU166 \\
\hline 8. & Epiquinine & -6.4 & -6.83 & GLU166 \\
\hline 9. & Procurcumenol & -6.6 & -7.11 & GLU166,HIS163 \\
\hline 10. & Quinidine & -6.6 & -7.26 & GLN189 \\
\hline 11. & Quinine & -6.1 & -7.48 & GLN189 \\
\hline 12. & Zedoaronediol & -6.1 & -6.56 & GLU166,GLN189 \\
\hline 13. & Procurcumadiol & -5.8 & -6.79 & GLU166,GLU189 \\
\hline 14. & N3 & -7.04 & -7.04 & PHE140,GLU166,HIS163 \\
\hline
\end{tabular}


The binding energies estimated for the filtered chemical constituents were in the range of -6.56 to $-8.38 \mathrm{kcal} / \mathrm{mol}$. The specific interactions of chemical constituent with $\mathrm{M}^{\text {pro }}$ is depicted in Figure 2 in comparison to the standard. It was identified from the literature sources that Glutamate at P1 position is a major requirement and seven active constituents showed interactions with GLU166 except cinchonidine, epicatechin, quinine and quinidine. The other major interactive amino acids surrounding the docked complex include HIS163, HIS164, LYS145, PRO168, ARG188, GLN189, GLN192, CYS145, LEU141, and THR190.

Catechin showed the highest binding energy of $-8.38 \mathrm{kcal} / \mathrm{mol}$. There were significant interactions with the receptor binding site including GLN166, LEU167, PRO168, HIS164, MET165, and CYS145 (Figure 3). It was found to form four prominent hydrogen bonds with THR190, GLN192, GLU166, and ASP187. The five hydroxyl groups in catechin are freely available to form multiple hydrogen bonds. It is further evident from the previous studies that the co-crystallised ligand N3 was found to show similar interactions. The effectiveness of catechin as an antiviral agent could be tested against COVID-19. But it should also be noted that many polyphenolic compounds are metabolized into their conjugated forms and accumulation of metabolized compounds are different among various tissues.

Epicatechin is an isomer of catechin with cisconfiguration and forms five hydrogen bond with GLN192, THR190, GLN 189, HIS 164 and ASP187.

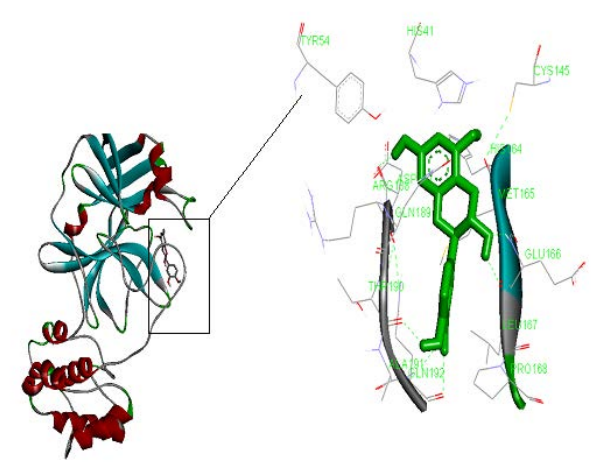

Figure 3. Docking pose of the constituent with highest docking energy Catechin and its interactions.
It had shown promising effects in the treatment of Mayaro fever caused due to the outbreak of Mayaro virus in Brazil. Epicatechin, a folklore medicine showed promising antiviral activity against hepatitis $\mathrm{C}$ virus, Mayaro virus and it was also observed that it had the ability to inhibit the viral replication in lower doses than the cytotoxic dose. A lower binding energy of $-7.29 \mathrm{kcal} / \mathrm{mol}$ further confirms a better binding towards the substrate and this could be considered as an potential constituent in the treatment of COVID-19.

Analyzing the interactions of procurcumenol from turmeric, showed three major hydrogen bonds with the amino acids HIS163 and GLU166. The previous research studies on curcumin has shown better antiviral activities against hepatitis $C$ virus and used in treatment of jaundice and other liver diseases. Liver impairment is seen as an arising concern of patients with COVID-19 due to the administration of high doses of potentially hepatotoxic antivirals, antibiotics and steroids. Zedoaronediol and procurcumadiol from curcumin showed three hydrogen bonding, of which two are with GLU166 and one with GLU189 with a binding energy of $-6.56 \mathrm{kcal} / \mathrm{mol}$ and $-6.79 \mathrm{kcal} /$ mol respectively. The physicochemical properties of the thirteen active constituent are provided in Table 4. The toxicity of the active constituents along with its HOMO, LUMO calculation are reported in Tables 5 and 6 respectively.

\section{Conclusion}

All the thirteen chemical constituents showed better binding affinity than the standard. From the docking study conducted, it could be understood that in most of the constituents the interaction of the ligand with the receptor through formation of hydrogen bond with aminoacid GLU166 marks its step in substrate recognition thereby necessitating the inhibitory mechanism. Epicatechin and apoquinine showed highest binding affinity of -7 and $-7.5 \mathrm{kcal} / \mathrm{mol}$ while catechin and epicatechin showed four hydrogen bond interactions leading to locking of the inhibitor in the binding pocket in a better way. It is interesting and worth noticing the interaction of GLU166 residue with the ligand in most of the constituents. Furthermore, studies on the dynamics of the best scoring constituent 
Table 4. The physicochemical properties of the best thirteen ligands

\begin{tabular}{ccccccc}
\hline S.No & PUBCHEM ID & $\begin{array}{c}\text { Physicochemical } \\
\text { Properties } \mathbf{M W} \\
(\mathbf{g} / \mathbf{m o l})\end{array}$ & LogP $(\mathbf{o} / \mathbf{w})$ & H-Acc & H-Bond & TPSA \\
\hline 1. & 310.39 & 2.34 & 4 & 2 & 56.59 \\
2. & 101600159 & 290.27 & 0.85 & 6 & 5 & 110.38 \\
3. & 9064 & 294.39 & 2.78 & 3 & 1 & 36.36 \\
4. & 101744 & 294.39 & 2.78 & 3 & 1 & 36.36 \\
5. & 90454 & 352.43 & 2.77 & 5 & 1 & 62.66 \\
6. & 54991 & 290.27 & 0.85 & 6 & 5 & 110.38 \\
7. & 12276 & 234.33 & 2.71 & 2 & 1 & 37.30 \\
8. & 10448938 & 324.42 & 2.81 & 4 & 1 & 45.59 \\
9. & 189061 & 234.33 & 2.71 & 2 & 1 & 37.30 \\
10. & 441074 & 324.42 & 2.81 & 4 & 1 & 45.59 \\
11. & 3034034 & 324.42 & 2.81 & 4 & 1 & 45.59 \\
12. & 101792719 & 252.35 & 2.09 & 3 & 2 & 57.53 \\
13. & 14633011 & 250.33 & 1.98 & 3 & 2 & 57.53 \\
\hline
\end{tabular}

Table 5. The mutagenicity and carcinogenicity prediction of the best thirteen ligands

\begin{tabular}{|c|c|c|c|c|c|}
\hline S.No & $\begin{array}{l}\text { PUBCHEM } \\
\text { ID }\end{array}$ & $\begin{array}{l}\text { Negative for } \\
\text { genotoxic } \\
\text { carcinogenicity }\end{array}$ & $\begin{array}{l}\text { Negative for } \\
\text { nongenotoxic } \\
\text { carcinogenicity }\end{array}$ & $\begin{array}{c}\text { Potential Salmonella } \\
\text { typhimurium TA100 } \\
\text { mutagen based on } \\
\text { QSAR }\end{array}$ & $\begin{array}{c}\text { Potential carcinogen } \\
\text { based on QSAR }\end{array}$ \\
\hline 1. & 101600159 & Yes & Yes & No & No \\
\hline 2. & 9064 & Yes & Yes & No & No \\
\hline 3. & 101744 & Yes & Yes & No & No \\
\hline 4. & 90454 & Yes & Yes & No & No \\
\hline 5. & 54991 & Yes & Yes & No & No \\
\hline 6. & 72276 & Yes & Yes & No & No \\
\hline 7. & 10263440 & No & Yes & No & No \\
\hline 8. & 10448938 & Yes & Yes & No & No \\
\hline 9. & 189061 & No & Yes & No & No \\
\hline 10. & 441074 & Yes & Yes & No & No \\
\hline 11. & 3034034 & Yes & Yes & No & No \\
\hline 12. & 101792719 & No & Yes & No & No \\
\hline 13. & 14633011 & No & Yes & No & No \\
\hline
\end{tabular}


Table 6. $\mathrm{E}_{\text {Hомо }}$ and $\mathrm{E}_{\mathrm{LUMO}}$ of best six chemical constituents and two standard ligands

\begin{tabular}{|c|c|c|c|c|c|c|}
\hline S.No & Molecule & номо & $\begin{array}{c}E \\
\text { HOMO }\end{array}$ & LUMO & E LUMO & $\begin{array}{c}\text { Energy gap } \\
(\mathrm{eV})\end{array}$ \\
\hline 1 & Catechin & & -8.26652 & & -4.26286 & -4.00366 \\
\hline 2 & Epicatechin & & -8.23468 & & -4.23489 & -3.99979 \\
\hline 3 & Epiprocurcumenol & & -9.42708 & & -5.52443 & -3.90265 \\
\hline 4 & Procurcumenol & & -9.35143 & & -5.50457 & -3.84686 \\
\hline 5 & Zedoaronediol & & -9.22898 & & -4.77068 & -4.4583 \\
\hline 6 & Procurcurmadiol & & -9.16177 & & -5.32416 & -3.83761 \\
\hline
\end{tabular}




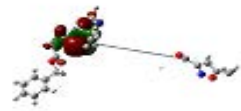

$-6.74105$

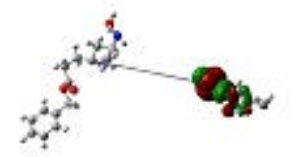

$-5.99655$

$-0.7445$

8

Favipravir

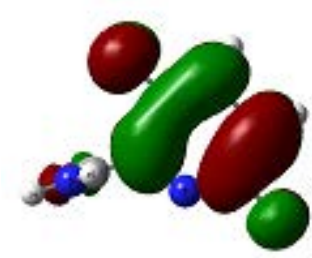

$-7.78079$

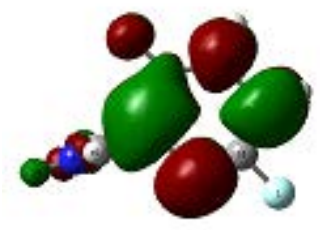

$-4.64578$

$-3.13501$ would help to understand the stability of the constituent in the binding site. The effectiveness of catechin and epicatechin as an antiviral agent could be tested against COVID-19.

\section{References}

1. WHO. Naming the coronavirus disease (COVID-19) and the virus that causes it [Internet]. [cited $2020 \mathrm{Apr}$ 8]. Available from: https://www.who.int/emergencies/ diseases/novel-coronavirus-2019/technical-guidance/ naming-the-coronavirus-disease-(covid-2019)-and-thevirus-that-causes-it.

2. Liu RP, Ge J De, Zhong Y, Zheng Q, Sun R. Traditional Chinese medicine for treatment of COVID-19 based on literature mining of targeting cytokine storm. Chinese Traditional and Herbal Drugs. 2020; 51(5):1096-105.

3. Li Y, Liu X, Guo L, Li J, Zhong D, Zhang Y, Clarke M, Jin R. Traditional Chinese herbal medicine for treating novel coronavirus (COVID-19) pneumonia: Protocol for a systematic review and meta-Analysis. Systematic Reviews. 2020; 9(1). https://doi.org/10.1186/s13643020-01343-4. PMid:32268923 PMCid:PMC7138957

4. Lerner K. SARS, MERS, and the Emergence of coronaviruses. Worldmark Global Health and Medicine Issues [Internet]. 2016. Available from:

5. Yan R, Zhang Y, Li Y, Xia L, Guo Y, Zhou Q. Structural basis for the recognition of SARS-CoV-2 by full-length human ACE2. Science. 2020; 367(6485):1444-8. https:// doi.org/10.1126/science.abb2762. PMid:32132184. PMC id:PMC7164635.

6. Ludwig S, Zarbock A. Coronaviruses and SARSCoV-2: A Brief Overview. Anesthesia and Analgesia.
2020. https://doi.org/10.1213/ANE.0000000000004845. PMid:32243297. PMCid:PMC7173023

7. Wang X, Xu W, Hu G, Xia S, Sun Z, Liu Z, et al. SARSCoV-2 infects $\mathrm{T}$ lymphocytes through its spike proteinmediated membrane fusion. Cellular and Molecular Immunology. 2020. https://doi.org/10.1038/s41423-0200424-9

8. Wang Q, Zhang Y, Wu L, Niu S, Song C, Zhang Z, et al. Structural and functional basis of SARS-CoV-2 entry by using human ACE2. Cell. 2020. https://doi.org/10.1016/j. cell.2020.03.045. PMid:32275855 PMCid:PMC7144619

9. Kaladhar SVGKD. Effects of drugs on spike glycoprotein of sars-cov 2 in control of covid-2019. International Journal of Advanced Research. 2020; 8(3):918-24. https://doi.org/10.21474/IJAR01/10706

10. Law S, Leung AW, Xu C. Severe Acute Respiratory Syndrome (SARS) and Coronavirus disease-2019 (COVID-19): From causes to preventions in Hong Kong. International Journal of Infectious Diseases. 2020; 94:156-63. https://doi.org/10.1016/j.ijid.2020.03.059. PMid:32251790 PMCid:PMC7195109

11. Giron CC, Laaksonen A, Silva FLB da. pbioRxiv. 2020;2020.04.05.026377.

12. Rut W, Groborz K, Zhang L, Sun X, Zmudzinski M, Hilgenfeld $R$, et al. Substrate specificity profiling of SARS-CoV-2 Mpro protease provides basis for antiCOVID-19 drug design. bioRxiv. 2020. https://doi. org/10.1101/2020.03.07.981928. PMid:32014497

13. Rabaan AA, Al-ahmed SH, Sah R, Tiwari R, Iqbal M, Patel SK, et al. SARS-CoV-2 / COVID-19 and advances in developing potential therapeutics and vaccines to counter this emerging pandemic virus - A Review. 
Preprints. 2020; 4:1-46. https://doi.org/10.20944/ preprints202004.0075.v1

14. Bharath EN, Manjula SN, Vijaychand A. In silico drug design-tool for overcoming the innovation deficit in the drug discovery process. International Journal of Pharmacy and Pharmaceutical Sciences. 2011; 3(2):812.

15. Ang L, Lee HW, Choi JY, Zhang J, Soo Lee M. Herbal medicine and pattern identification for treating COVID-19: A rapid review of guidelines. Integrative Medicine Research. 2020; 9(2):100407. https://doi. org/10.1016/j.imr.2020.100407. PMid:32289016 PMCid: PMC7104236

16. Ferner RE, Aronson JK. Chloroquine and hydroxychloroquine in covid-19. The BMJ. 2020; 369. https://doi.org/10.1136/bmj.m1432. PMid:32269046

17. Atallah P, Wagener KB, Schulz MD. ADMET: The future revealed. Macromolecules. 2013. https://doi. org/10.1002/chin.201336195

18. López-López E, Naveja JJ, Medina-Franco JL. DataWarrior: An evaluation of the open-source drug discovery tool. Expert Opinion on Drug Discovery. 2019. https://doi.org/10.1080/17460441.2019.1581170. PMid:30806519

19. Trott O, Olson AJ. Autodock vina: Improving the speed and accuracy of docking. Journal of Computational Chemistry. 2019; 31(2):455-61.
20. Lindstrom W, Morris GM, Weber C, Huey R. Using AutoDock for virtual screening. The Scripps Research Institue [Internet]. 2006. Available from:

21. Lin LT, Hsu WC, Lin CC. Antiviral natural products and herbal medicines. Journal of Traditional and Complementary Medicine. 2014; 4(1):24-35. https:// doi.org/10.4103/2225-4110.124335. PMid:24872930 PMCid:PMC4032839

22. Jin Z, Du X, Xu Y, Deng Y, Liu M, Zhao Y, et al. Structure of Mpro from COVID-19 virus and discovery of its inhibitors. Nature. 2020. https://doi.org/10.1101/2020.02.26.964882

23. Lohidashan K, Rajan M, Ganesh A, Paul M, Jerin J. Pass and Swiss ADME collaborated in silico docking approach to the synthesis of certain pyrazoline spacer compounds for dihydrofolate reductase inhibition and antimalarial activity. Bangladesh Journal of Pharmacology. 2018; 13(1):23-9.https://doi.org/10.3329/bjp.v13i1.33625

24. Contrera JF. Validation of Toxtree and SciQSAR in silico predictive software using a publicly available benchmark mutagenicity database and their applicability for the qualification of impurities in pharmaceuticals. Regulatory Toxicology and Pharmacology. 2013; 67(2):285-93. https://doi.org/10.1016/j.yrtph.2013.08.008. PMid: 23969001 